\title{
Potential roles of exosome non-coding RNAs in cancer chemoresistance (Review)
}

\author{
YUEYUE WANG, QIAN LIU and FENGCHAO WANG \\ Department of Clinical Laboratory, The First Affiliated Hospital of Bengbu Medical College, \\ Bengbu, Anhui 233004, P.R. China
}

Received July 18, 2020; Accepted November 11, 2020

DOI: $10.3892 /$ or.2020.7887

\begin{abstract}
Multiple studies have demonstrated chemoresistance in multiple types of tumor, which limits the effectiveness of cancer treatments. Chemoresistance often contributes to cancer relapse. Non-coding RNAs, are a group of regulatory RNAs, that are involved in tumor drug resistance. Exosomes, membranous vesicles secreted by cells, are reported to mediate cell-to-cell communication, including in cancer. Furthermore, exosomal non-coding RNAs have been reported to mediate chemoresistance via exchange of biological information. In the present review, the main roles of exosomal non-coding RNAs, including micro(mi) RNAs, long non-coding (lnc) RNAs, and circular (circ) RNAs in cancer are described and their potential roles in chemoresistance in various types of cancer are also discussed.
\end{abstract}

\section{Contents}

1. Introduction

2. Non-coding RNAs: Definition, features, biogenesis, and functions

3. Exosomes: Origins, biogenesis, and functions

4. Significance of exo-miRNAs in cancer chemoresistance

5. Significance of exo-lncRNAs in cancer chemoresistance

6. Significance of exo-circRNAs in cancer chemoresistance

7. Conclusion

\section{Introduction}

Cancer is a leading cause of death, with increasing incidence and mortality rates, worldwide. Globally, there were an

Correspondence to: Dr Fengchao Wang, Department of Clinical Laboratory, The First Affiliated Hospital of Bengbu Medical College, 287 Chang Huai Road, Bengbu, Anhui 233004, P.R. China E-mail: 13855215344@139.com

Key words: exosome, long non-coding RNAs, microRNAs, circular RNAs, cancer, chemoresistance estimated 18.1 million new cancer cases and 9.6 million cancer-associated deaths in 2018. More than $50 \%$ of the cancer-associated deaths occurred in Asia (1,2). Effective chemotherapy is beneficial against cancer; however, the development of chemoresistance, whether intrinsic or acquired, is the primary concern to ensure good outcomes, and contributes to distant metastasis, tumor recurrence, and disease deterioration, resulting in cancer progression (3). Chemoresistance may result from various factors, including increased drug efflux pumps, resistance to apoptosis, DNA repair defects, and mutations affecting drug targets (4-7). Thus, it is crucial to identify mechanisms underlying chemotherapy to improve cancer outcomes.

Advances in whole genome and transcriptome sequencing technologies have revealed that non-coding (nc) RNAs modulate disease pathogenesis at the cellular and molecular levels (8). ncRNAs include microRNAs (miRNA/miR), long non-coding (lnc) RNAs, circular (circ) RNAs, small nuclear RNAs, small nucleolar RNAs, small interfering RNAs, and piwi-interacting RNA. Of these, miRNAs, IncRNAs, and circRNAs are known to regulate cancer cell proliferation, invasion and metastases, at the transcriptional and post-transcriptional levels (9). Recent studies have shown that ncRNAs was associated with cancer cell chemoresistance. For example, GBCDRlnc1, a lncRNA, was reported to induce chemoresistance in gallbladder cancer cells by interacting with phosphoglycerate kinase 1 and upregulating autophagy-related gene levels (10). CRIM1, a circRNA, has been shown to promote nasopharyngeal cancer metastasis and docetaxel chemoresistance by competitively binding Forkhead box Q1 (11). While these findings show that ncRNAs may modulate cancer chemotherapy, the underlying mechanisms are unclear.

Exosomes, which are 30-100 $\mathrm{nm}$ in diameter, are nanoscale membrane vesicles derived from endosomal multivesicular bodies released by various cell types, including immune cells, neurons, mesenchymal stem cells, Schwann cells and epithelial cells (12) and have been associated with cancer growth, metastasis and chemoresistance (13-15). Exosomes carry various cargo, including DNAs, RNAs and proteins, that are involved in the exchange of genetic information between donor and recipient cells in tumor microenvironments, which may transmit drug resistance $(13,16)$. In the present review, research on exosomal ncRNAs in different types of cancer, 
will be discussed, with the aim to highlight their role in cancer treatment.

\section{Non-coding RNAs: Definition, features, biogenesis, and functions}

Non-coding RNAs comprise $\sim 98 \%$ of the human genome, which was once considered to be transcriptional noise (17). Extensive research has revealed that ncRNAs regulate various molecular processes and human diseases (18).

miRNAs are small ncRNAs, comprised of 20-22 nucleotides in length, excised from 60-110 nucleotide foldback RNA precursor structures (19) and are widely expressed in various types of cancer, including breast, gastric, and colorectal cancer, and have been associated with prognosis (20-22).

lncRNAs, which are $>200$ nucleotides in length, do not encode protein (23), but regulate transcription in cis or trans by modulating mRNA processing, post-transcriptional control, protein activity, and organization of nuclear domains (24). Advances in next-generation sequencing have revealed that IncRNA dysregulation has been associated with tumorigenesis, cancer growth, invasion, autophagy, and chemoresistance (25-28).

circRNAs are single-stranded covalently closed RNA molecules, that were first identified in RNA viruses in 1976 using electron microscopy (29). circRNAs fall into four different types: Exon circRNAs, circular intronic RNAs, exon-intron circRNAs, and intergenic circRNAs or fusion circRNAs (30-32). circRNAs are protected from RNase digestion, as they lack free $5^{\prime}$ and $3^{\prime}$ structures, therefore they are more stable than linear RNAs (33). Functionally, circRNAs modulate gene expression transcriptionally and post-transcriptionally, in physiological and pathological contexts, primarily by acting as miRNA sponges. For example, circ-TCF4.85 has been reported to promote hepatocellular carcinoma (HCC) development by competitively binding to miR-486-5p (34). Hsa_circ_0091570 knockdown significantly enhanced cell proliferation and migration, and inhibited apoptosis in HCC by sponging miR-1307 (35).

\section{Exosomes: Origins, biogenesis, and functions}

Exosomes were first described in 1983, as vesicles with a 30-100 nm diameter (36-38). Exosomes mainly originate from multivesicular bodies, through membrane invagination. This process produces intraluminal vesicles under the control of the Endosomal Sorting Complex Required for Transport proteins (39). The main surface exosomal markers are CD9, CD81, CD82, and TSG101 (40). Exosomes are released by various cell types, including T-cells, B-cells, dendritic cells, and mesenchymal stem cells (MSCs), and have been found to be enriched in various body fluids, including serum, plasma, saliva, milk, urine, and cerebrospinal fluid (41-43). Exosomes are involved in intercellular communication under physiological and pathological conditions (44). They can transfer active components like DNA, RNA (coding and non-coding) and proteins from donor to recipient cells, thereby exerting regulatory effects on them (45) (Fig. 1). Tumor-derived exosomes may contribute to tumorigenesis, metastasis, tumor microenvironments, and chemoresistance $(46,47)$. However, the exact mechanisms by which exosomes act in tumors requires further investigation.

\section{Significance of exo-miRNAs in cancer chemoresistance}

There is an increasing number of studies which have shown that exosomes contain specific miRNAs in response to cancer therapy, resulting in chemoresistance or chemosensitivity in body fluids $(48,49)$ (Table I). Exosomes have been found to transfer miR-196a to recipient cells, promoting cisplatin resistance by sponging CDKN1B and ING5 in plasma and tissues from patients with head and neck cancer (50). Exosomal miR-1238 derived from resistant cancer cells could confer drug resistance to sensitive cells by activating the EGFR-PI3K-Akt-mTOR signaling pathway (51). In tumors from the digestive system, miR-374a-5p was found to be upregulated in the serum from patients with gastric cancer and was associated with poor prognosis (52). miR-374a-5p suppressed apoptosis and increased the expression of multi-drug resistant and topoisomerase II by negatively regulating its target gene, Neurod1. In addition, inhibition of exosome-mediated miR-374a-5p activity may re-sensitize gastric cancer cells to oxaliplatin (52). Reduced miR-744 expression levels were reported in the exosomes from serum and tissues in patients with $\mathrm{HCC}(53,54)$. PAX2 was found to be upregulated in HCC tissue and was a miR-744 target. Knockdown and overexpression functional assays found that HepG2-resistant cells treated with miR-744-overexpressing exosomes were more sensitive to sorafenib. Treating HCC cells with exosomes from mature adipocytes transferred $\mathrm{miR}-23 \mathrm{a} / \mathrm{b}$ to them, conferring 5-fluorouracil resistance and an aggressive phenotype. These findings indicated that exosomal miR-744 or miR-23a/b are potential HCC biomarkers $(53,54)$. miR-196b-5p promoted chemoresistance to 5 -fluorouracil by targeting negative regulators of SOCS (suppressor of cytokine signaling)-1 and -3 in colorectal cancer, activating the STAT3 signaling pathway. In addition, miR-196b-5p expression in serum exosomes from patients with colorectal cancer was markedly higher compared with that in healthy controls (55).

Gene function and bioinformatics analyses revealed that miR-23a-3p, miR-27a-3p, miR-30a-5p, and miR-320a were markedly upregulated in exosomes derived from adriamycin-resistant cells compared with that in parental breast cancer cells (56). These miRNAs may contribute to chemoresistance via multiple signaling pathways, including the MAPK, and Wnt signaling pathways (56). Furthermore, 14 miRNAs were found to be significantly elevated in oxaliplatin/5-fluorouracil resistant colorectal cancer cells compared with that in the control parental cells (49). Of these, miR-21-5p, miR-1246, miR-1229-5p, miR-135b, miR-425, and miR-96-5p were highly abundant in exosomes from the resistant cells. In addition, exosomal miR-21-5p, miR-1246, miR-1229-5p and miR-96-5p levels in the serum of patients with colorectal cancer (CRC) who were chemoresistant were markedly higher compared with that in patients who were chemosensitive. Notably, Gene Ontology and Kyoto Encyclopedia of Genes and Genomes analysis revealed that these miRNAs were enriched in the PI3K-AKT, FOXO, and autophagy pathways. These 4 exosomal miRNAs could be potential biomarkers for chemoresistance restoration in colorectal cancer (49). Signaling pathways have 


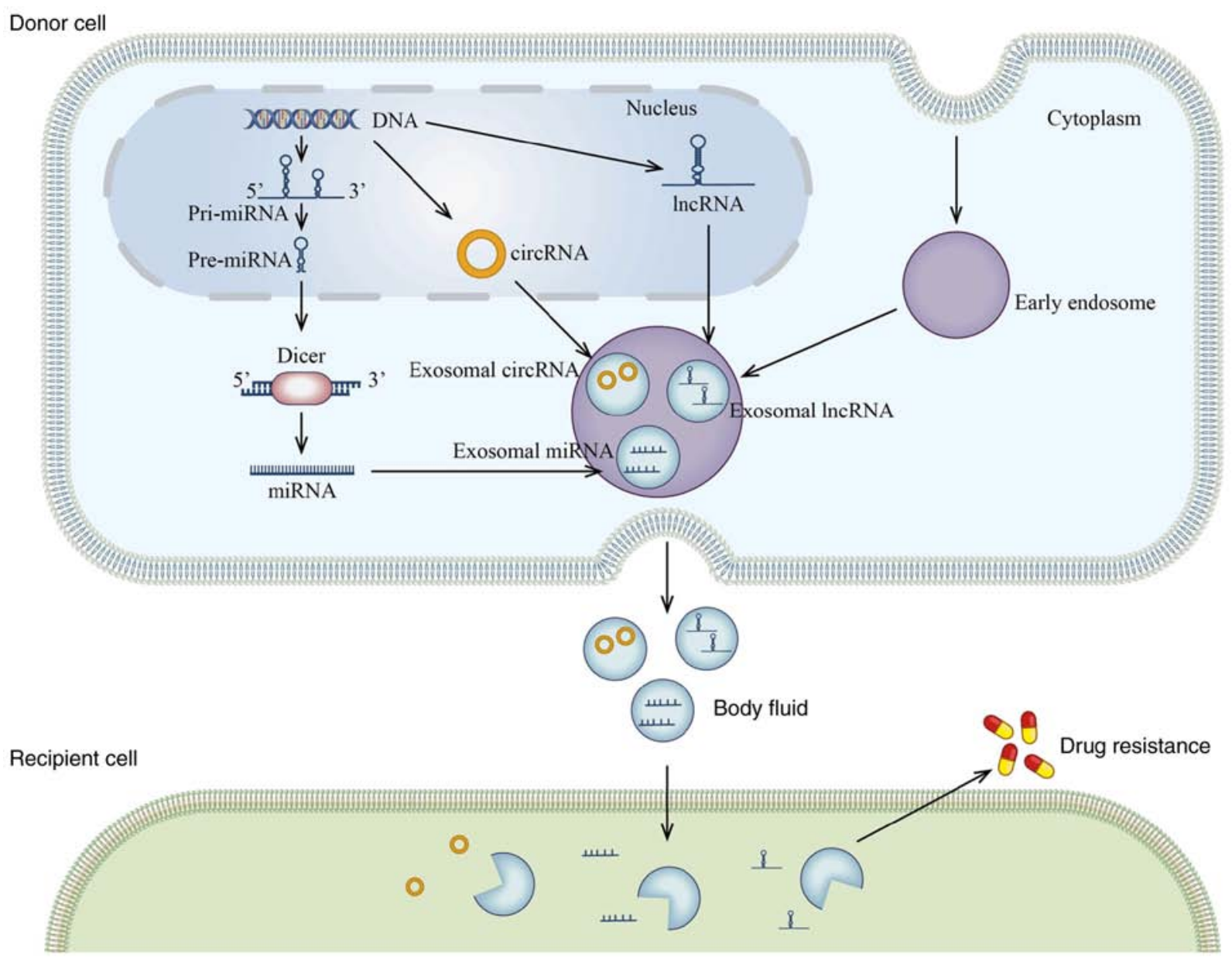

Figure 1. Schematic illustration of exosome non-coding RNAs biogenesis and release on the development of chemoresistance. Circ, circular; lnc, long non-coding; mi, micro.

been found to be involved in miRNA-mediated chemoresistance via tumor exosomes. For example, exosome-mediated transfer of miR-21 promoted cisplatin resistance via the PTEN/PI3K/AKT signaling pathway (57). Exosomal transfer of miR-142-3p from bone marrow-derived MSCs suppressed Numb expression, activating the Notch signaling pathway (58).

Intercellular communication was found to be initiated by surface interactions between circulating exosomes and transmembrane molecules expressed on target cells. The release and uptake of exosomes, containing miRNAs, are a crucial form of cell-cell communication in tumors, as cells acquire malignant phenotypes by engulfing tumor-derived oncogenic factors in the exosomes (59). In addition to cancer cells, cancer-associated fibroblasts (CAFs) are innately chemoresistant and contribute to cancer cell chemoresistance (60). CAF-derived miR21 was reported to be significantly upregulated in ovarian cancer cells. Exosomes carrying miR21 from CAFs to recipient cells conferred chemoresistance and aggressive phenotypes (61). Furthermore, as CAFs are intrinsically resistant to cisplatin, their exosomes accelerated resistance (50). CAF-derived exosomes transferred miR-196a to head and neck cancer (HNC) cells, promoting proliferation and cisplatin resistance, which was mediated by nuclear ribonucleoprotein A1. Functionally, miR-196a conferred cisplatin resistance by suppressing the expression level of CDKN1B and ING5, both in the plasma and tissues from patients with $\mathrm{HNC}$, indicating that miR-196a might be an independent predictor for chemoresistance in patients with head and neck cancer (50). CAFs constitute the bulk of pancreatic ductal adenocarcinoma (PDAC) tumors and promote epithelial cancer cell proliferation and drug resistance. Gemcitabine-treated CAF exosomes enhanced proliferation and survival of chemoresistant PDAC cells (62). miRNA-sequencing analysis found that miR-146a was markedly elevated in gemcitabine-treated fibroblasts. Compared with that in untreated CAFs, gemcitabine-treated CAFs expressed significantly higher miR-146a expression levels. Gemcitabine-treated CAFs derived exosomes were also found to elevate Snail and miR-146a expression levels. These data suggest that CAF-derived exosomes are key modulators of PDAC chemoresistance. However, blocking exosome release may suppress chemoresistance caused by exosome-mediated signaling (62). In recent decades, cancer stem cells (CSCs) have emerged as a unique cellular subtype capable of self-renewal and multi-differentiation. CSCs are important drivers of cancer recurrence, metastases, and chemoresistance (63). Santos et al (64) found that breast cancer cells were more resistant to doxorubicin (DOX) upon receiving exosomes from DOX- and paclitaxel-resistant CSCs compared with that in sensitive cells, suggesting that exosomes transfer drug-resistance. In addition, miR-155 overexpression increased its content in exosomes, leading to epithelial-mesenchymal transition (EMT)-associated chemoresistance. Furthermore, 
Table I. miRNAs involved in chemotherapy.

\begin{tabular}{|c|c|c|c|c|c|c|}
\hline $\begin{array}{l}\text { Cancer } \\
\text { type }\end{array}$ & miRNA & Exosome origin & Drug & $\begin{array}{l}\text { Regulation of } \\
\text { chemoresistance }\end{array}$ & Related genes & (Refs.) \\
\hline $\mathrm{HNC}$ & miR-196a & Cell/plasma/tissue & DDP & Promotion & $\begin{array}{l}\text { hnRNPA1, CDKN1B, } \\
\text { ING5 }\end{array}$ & $(50)$ \\
\hline \multirow[t]{2}{*}{ GBM } & miR-151a & Cell/serum/CSF & TMZ & Inhibition & XRCC4 & $(48)$ \\
\hline & $\operatorname{miR}-1238$ & Cell/serum & TMZ & Promotion & CAV1 & $(51)$ \\
\hline OSCC & $\operatorname{miR}-21$ & Cell & DDP & Promotion & PTEN, PDCD4 & (6) \\
\hline NSCLC & $\operatorname{miR}-425-3 p$ & Cell/serum & DDP & Promotion & AKT1, c-Myc & $(68)$ \\
\hline \multirow[t]{6}{*}{ GC } & miR-501 & Cell & DOX & Promotion & BLID & (7) \\
\hline & $\operatorname{miR}-374 a-5 p$ & Cell/serum & OXA & Promotion & Neurod1 & $(52)$ \\
\hline & miR-214 & Cell/serum & DDP & Promotion & PARP9 & $(90)$ \\
\hline & miR-21 & Cell & DDP & Promotion & PTEN/PI3K/AKT & $(57)$ \\
\hline & $\operatorname{miR}-155-5 p$ & Cell & PTX & Promotion & TP53INP1, GATA3 & $(67)$ \\
\hline & $\begin{array}{l}\operatorname{miR}-106 a-5 p \\
\operatorname{miR}-421\end{array}$ & Cell & $5-\mathrm{FU}$ & Promotion & E2F1, STAT3 & $(91)$ \\
\hline \multirow[t]{2}{*}{$\mathrm{HCC}$} & miR-744 & Cell/serum/tissue & Sorafenib & Inhibition & PAX2 & $(53)$ \\
\hline & microRNA-23a/b & Cell/serum & $5-\mathrm{FU}$ & Promotion & VHL/HIF-1 $\alpha$ & $(54)$ \\
\hline \multirow[t]{3}{*}{$\mathrm{PC}$} & miR-155 & Cell/serum/tissue & GEM & Promotion & TP53INP1 & $(5)$ \\
\hline & miR-146a & Cell & GEM & Promotion & Snail & $(62)$ \\
\hline & $\operatorname{miR}-155$ & Cell & GEM & Promotion & DCK & $(92)$ \\
\hline \multirow[t]{9}{*}{ CRC } & $\begin{array}{l}\text { miR-21-5p } \\
\text { miR-1246 } \\
\text { miR-1229-5p } \\
\text { miR-96-5p }\end{array}$ & Serum & OXA/5-FU & Promotion & NA & $(49)$ \\
\hline & miR-196b-5p & Cell/ serum & $5-\mathrm{FU}$ & Promotion & STAT3 & $(55)$ \\
\hline & $\operatorname{miR}-128-3 p$ & Cell & OXA & Inhibition & Bmi1 MRP5 & $(66)$ \\
\hline & $\operatorname{miR}-46146$ & Cell & OXA & Promotion & PDCD10 & $(93)$ \\
\hline & $\operatorname{miR}-142-3 p$ & Cell/tissue & DOX & Promotion & Numb & $(58)$ \\
\hline & $\operatorname{miR}-155$ & Cell & DOX, PTX & Promotion & TGF- $\beta$ & (64) \\
\hline & miRNAs & Cell & DTX & Promotion & D Rhamnose $\beta$-hederin & (94) \\
\hline & $\begin{array}{l}\operatorname{miR}-9-5 p \\
\text { miR-195-5p } \\
\text { miR-203a-3p }\end{array}$ & Cell & DTX & Promotion & ONECUT2 & $(65)$ \\
\hline & miR-126a & Cell & DOX & Promotion & S100A8/9a & (69) \\
\hline \multirow[t]{4}{*}{$\mathrm{OC}$} & $\operatorname{miR} 21$ & Cell & PTX & Promotion & APAF1 & (61) \\
\hline & $\operatorname{miR}-223$ & Cell/serum/tissue & Platinum & Promotion & PTEN & (70) \\
\hline & miR-1246 & Cell & PTX & Promotion & Cav1 & $(95)$ \\
\hline & miR-433 & Cell & PTX & Promotion & $\begin{array}{l}\text { CDK6, MAPK14, } \\
\text { E2F3, CDKN2A }\end{array}$ & (96) \\
\hline
\end{tabular}

HNC, head and neck cancer; GBM, glioblastoma; OSCC, oral squamous cell carcinoma; NSCLC, non-small cell lung cancer; GC, gastric cancer; HCC, hepatocellular carcinoma; PC, pancreatic ductal adenocarcinoma; CRC, colorectal cancer; BC, breast cancer; OC, ovarian cancer; CSF, cerebrospinal fluid; DDP, cisplatin; TMZ, temozolomide; DOX, doxorubicin; OXA, oxaliplatin; PTX, paclitaxel; 5-FU, 5-fluorouracil; GEM, gemcitabine; miRNA/miR, microRNA.

co-culture assays revealed that the exosome-transferred miR-155 significantly induced DOX and paclitaxel resistance in breast cancer cells. The study by Santos et al (64) highlighted the importance of inhibiting transfer of drug-resistance from resistant breast cancer cells to sensitive ones. One cut homeobox 2 promoted breast cancer cell growth and its overexpression may suppress stemness-associated gene expression via chemoresistant extracellular vesicles (EVs), aiding the reverse of chemoresistance (65). This mechanism was negatively mediated by miR-9-5p, miR-195-5p, and miR-203a-3p in circulating EVs (65). Thus, cell-cell communication via exosomal miRNAs may be an important mechanism for cancer chemotherapy.

EMT contributes to cancer chemoresistance. miR-128-3p has been reported to suppress EMT and enhance intracellular oxaliplatin accumulation in colorectal cancer. Delivery of 
Table II. IncRNAs and circRNAs in chemotherapy.

\begin{tabular}{|c|c|c|c|c|c|c|}
\hline $\begin{array}{l}\text { Cancer } \\
\text { type }\end{array}$ & lncRNA & Exosome origin & Drug & $\begin{array}{c}\text { Regulation of } \\
\text { chemoresistance }\end{array}$ & $\begin{array}{l}\text { Related gene } \\
\text { or miRNA }\end{array}$ & (Refs.) \\
\hline GBM & SBF2-AS1 & Cell/serum & TMZ & Promotion & $\begin{array}{l}\text { ZEB1, } \\
\text { miR-151a-3p, } \\
\text { XRCC4 }\end{array}$ & (84) \\
\hline OSCC & PART1 & Cell/serum & Gefitinib & Promotion & miR-129, STAT1 & (83) \\
\hline NSCLC & RP11-838N2.4 & Cell & Erlotinib & Promotion & FOXO1 & $(85)$ \\
\hline GC & HOTTIP & Cell & DDP & Promotion & $\begin{array}{l}\text { HMGA1/miR-218 } \\
\text { axis }\end{array}$ & $(82)$ \\
\hline $\mathrm{HCC}$ & ROR & Cell & Sorafenib or DOX & Promotion & $\mathrm{TGFb}$ & (12) \\
\hline \multirow[t]{2}{*}{ CRC } & CCAL & Cell & OXA/5-FU & Promotion & HuR, $\beta$-catenin & $(59)$ \\
\hline & H19 & Cell & OXA & Promotion & miR-141 & (76) \\
\hline \multirow[t]{4}{*}{$\mathrm{BC}$} & AGAP2-AS1 & Cell & Trastuzumab & Promotion & AUF1, ERBB2 & (73) \\
\hline & SNHG14 & Cell/serum & Trastuzumab & Promotion & Bcl-2, Bax & (74) \\
\hline & H19 & cell/serum & DOX & Promotion & NA & (75) \\
\hline & AFAP1-AS1 & Cell/serum/tissue & Trastuzumab & Promotion & AUF1, ERBB2 & (72) \\
\hline $\mathrm{OC}$ & Cdr1as & Cell & DDP & Inhibition & $\operatorname{miR}-1270$ & (86) \\
\hline \multirow[t]{2}{*}{ CRC } & hsa_circ_0000338 & Cell & $5-\mathrm{FU}$ & Promotion & NA & $(87)$ \\
\hline & ciRS-122 & Cell & OXA & Promotion & miR-122, PKM2 & $(88)$ \\
\hline GBM & circNFIX & Cell/serum & TMZ & Promotion & miR-132 & (89) \\
\hline
\end{tabular}

DDP, cisplatin; TMZ, temozolomide; DOX, doxorubicin; OXA, oxaliplatin; 5-FU, 5-fluorouracil; lnc, long non-coding; circ, circular; miRNA/miR, microRNA; NA, not applicable.

miR-128-3p to resistant cells via secreted exosomes improved oxaliplatin response (66). Delivery of miR-155-5p to MGC-803 cells, in tumor-derived exosomes induced EMT and chemoresistance by suppressing the expression level of GATA binding protein 3 expression and tumor protein p53-inducible nuclear protein 1 , highlighting a prospective strategy for reversing paclitaxel resistance in gastric cancer (67).

An increasing number of studies have shown that exosomal miRNAs also trigger tumor drug resistance via autophagy, angiogenesis, inflammation and hypoxia induction (68-70). Cisplatin elevated circulating exosomal miR-425-3p levels and exo-miRNA release in non-small cell lung cancer (68). Furthermore, exosomal miR-425-3p may target AKT1, activating autophagy by negatively regulating the AKT/mTOR signaling pathway and causing resistance to cisplatin-induced apoptosis (68). miR-126a was released from myeloid-derived suppressor cell exosomes, promoting lung metastasis induced by DOX (69). Hypoxia has been reported to induce macrophage M2-polarization and enhance the level of tumor-associated macrophage (TAM)-derived exosomal miR-223 (70). In addition, TAM-derived exosomal miR-223 was reported to modulate chemoresistance and exosmal miR-223 has been shown to inactivate the PI3K/AKT signaling pathway by targeting PTEN. Furthermore, circulating exosomal miR-223 predicted the response to chemotherapy in patients with advanced epithelial ovarian cancer (70). Taken together, exosomal miRNAs are potential non-invasive biomarkers and therapeutic targets in a new anti-cancer paradigm. The value of exosomal miRNAs as anti-chemoresistance targets warrants further Investigation.

\section{Significance of exo-IncRNAs in cancer chemoresistance}

lncRNAs, which were previously regarded as transcriptional junk, due to their lack of protein coding capacity, are involved in numerous biological processes at the transcriptional, post-transcriptional, and chromatin levels. An increasing number of studies have indicated that exosomal lncRNAs modulate chemoresistance (Table II).

Trastuzumab, a humanized monoclonal antibody against the extracellular region of human epidermal growth factor receptor 2 (HER-2) is used to treat HER2-positive breast cancer; however, its effects are limited by resistance (71). The lncRNA, actin filament associated protein 1 antisenseRNA 1 (AFAP1-AS1) has been reported to be elevated in trastuzumabresistant cells compared with that in sensitive cells, and was associated with poor prognosis and survival time in patients with breast cancer (72). In addition, knockdown of AFAP1-AS1 has been shown to reverse chemoresistance. Furthermore, AFAP1-AS1 was transferred from resistant cells to recipient cells by the incorporation of exosomes, inducing trastuzumab resistance. Mechanically, AFAP1-AS1 has been reported to promote ERBB2 translation by combining with AU-binding factor 1 (AUF1) protein. Thus, exosomal AFAP1-AS1 promoted trastuzumab resistance by binding to AUF1 (72). Similarly, the lncRNA, AGAP2 antisense RNA 1 (AGAP2-AS1) promoted trastuzumab resistance in breast cancer cells via packaging into exosomes (73). Exosomal small nucleolar RNA host gene 14 (SNHG14) lncRNA induced trastuzumab resistance by upregulating the Bcl-2/Bax signaling pathway. Serum exosomal SNHG14 has biomarker potential in breast cancer (74). 
Breast cancer cell-derived exosomes might enhance DOX resistance by transferring lncRNA H19. Serum exosomal H19 is highly expressed in patients who are non-responsive to DOX compared with that in patients who are responsive (75). Crosstalk between CAFs and cancer cells has been reported to promote tumor progression and induce chemoresistance in the tumor microenvironment. CAFs promoted stemness and chemoresistance by transmitting exosomal H19 in CRC. Mechanically, H19 mediated oxaliplatin resistance by activating the $\mathrm{WNT} / \beta$-catenin signaling pathway by sponging miR-141 (76). CAFs transferred CRC-associated lncRNA to tumor cells in exosomes, conferring oxaliplatin and 5 -fluorouracil resistance and activating the WNT/ $\beta$-catenin signaling pathway (59). The WNT/ $\beta$-catenin signaling pathway modulates various tumor processes, including cancer growth, invasion and angiogenesis $(77,78)$ and its abnormal activation may result in cancer drug resistance $(79,80)$.

Exosomal lncRNA dysregulation has been observed in different types of cancer, where they act as competitive endogenous RNAs against active factors, such as miRNAs $(76,81)$. In gastric cancer (GC), exosomes have been reported to downregulate HOXA at the distal tip, a lncRNA, hence conferring cisplatin resistance by sponging miR-218, highlighting a potential exosome lncRNA-directed therapy against GC (82). The lncRNA, prostate androgen-regulated transcript 1 (PART1) was abundantly expressed in gefitinib-resistant cells compared with that in parental esophageal squamous cell carcinoma cells (83). By binding to PART1's promoter region, signal transducer and activator of transcription participated in chemoresistance. In addition, exosome-mediated transfer of PART1 induced resistance by targeting miR-129. Furthermore, serum exosomal PART1 was stably upregulated in patients with esophageal squamous cell carcinoma who were also gefitinib-resistant (83). A binding site is often located in the promoter region of lncRNAs, and a gene can bind to this site to regulate expression, thus affecting tumor biology. For example, IncRNA SBF2 antisense RNA 1 (SBF2-AS1) overexpression contributed to temozolomide (TMZ) resistance in glioblastoma (GBM) cells, while its downregulation could reverse this effect (84). The transcription factor, ZEB1 combined with the promoter region of SBF2-AS1 to alter chemoresistance. SBF2-AS1-containing exosomes secreted by cancer cells transmitted TMZ to the recipient cells. SBF2-AS1-containing serum exosomes were associated with poor response to TMZ treatment in patients with GBM (84). Notably, acetylated histone 3 lysine 27 was enriched at the promoter region of AFAP1-AS1, which might trigger drug resistance (72). In non-small cell lung cancer (NSCLC), exosome-mediated transfer of IncRNA RP11-838N2.4 induced erlotinib resistance. Forkhead box protein $\mathrm{O} 1$ could bind to the promoter region of RP11-838N2.4, and silenced it by recruiting histone deacetylase. Therefore, IncRNA RP11-838N2.4 may be a valuable target for reversing NSCLC chemoresistance (85). Taken together, exosomal lncRNAs play important roles in transmitting chemoresistance. However, the regulatory mechanism of chemoresistance is unclear and warrants further investigation.

\section{Significance of exo-circRNAs in cancer chemoresistance}

Numerous studies have suggested that circRNAs are novel therapeutic and prognostic biomarkers for various types of cancer, due to their characteristics of closed loop structure and insensitivity to RNase. It is now known that exosomes might be carriers of circRNAs, which are subsequently secreted into body fluids, enabling them to modulate tumor cell proliferation, migration, invasion, and apoptosis, and to affect drug resistance. For example, the circRNA, Cdrlas, has been reported to be downregulated in serum exosomes from patients with cisplatin-resistant ovarian cancer (86). In CRC, hsa_circ_0000338 has been reported to have tumor suppressive function in CRC cells, so that they are sensitive to fluorouracil plus oxaliplatin. Clinical data has validated that hsa_circ_000338 was markedly downregulated in serum exosomes in patients with CRC who are chemo-resistant (87). Exosomes, from resistant CRC cells, transmitted ciRS-122 to recipient cells by sponging miR-122, thereby resulting in oxaliplatin resistance (88). Serum exosomal circNFIX has been reported to be upregulated in patients with glioma and who are TMZ-resistant (89). Extracellular circNFIX secretion in exosomes also conferred TMZ resistance in sensitive cells, while circNFIX silencing promoted TMZ sensitivity in resistant cells by negatively interacting with miR-132. This finding highlighted the role of prognostic biomarkers and promising therapeutic targets in improving the clinical benefits of TMZ in patients with glioma (89). However, further studies are required to improve the understanding of the roles of exo-circRNAs in overcoming chemoresistance.

\section{Conclusions}

Since their discovery, extensive research has shown that ncRNAs regulate multiple molecular processes. In addition, due to sequence conservation, they are more stably expressed in various types of tissues, cells, and body fluids. Recent studies have indicated that ncRNAs affect tumor chemoresistance; therefore, they are promising biomarkers for cancer therapy and reversal of chemoresistance (97-99). Despite the increasing number of studies on ncRNAs chemoresistance, they have not yet been targeted clinically.

Exosomes deliver various cargo, such as DNA, RNA and proteins, from donor cells to recipient cells, thus exerting biological effects. In recent years, it has emerged that exosome-mediated transfer of ncRNAs may enhance chemoresistance. The present review described the importance of exosome-contained ncRNA in cancer chemotherapy. However, their effects in cancer are still controversial, and most of the evidence only comes from cell-based and animal studies. Thus, comprehensive studies into the roles and mechanisms of exosome ncRNAs in different types of cancer may uncover novel effective treatment strategies. Thus, comprehensive clinical studies in this area are warranted.

\section{Acknowledgements}

Not applicable.

\section{Funding}

This study was supported by grants from the Natural Science Foundation of Anhui Province (grant no. 2008085QH404) 
and the Science Research Project of Bengbu Medical College (grant no. BYKY2019048ZD).

\section{Availability of data and materials}

Not applicable.

\section{Authors' contributions}

YYW and QL designed the study. YYW drafted the manuscript. YYW and QL designed the tables and figures. FCW critically discussed and revised the manuscript. All authors read and approved the final manuscript for publication.

\section{Ethics approval and consent to participate}

Not applicable.

\section{Patient consent for publication}

Not applicable.

\section{Competing interests}

The authors declare that they have no competing interests.

\section{References}

1. Bray F, Ferlay J, Soerjomataram I, Siegel RL, Torre LA and Jemal A: Global cancer statistics 2018: GLOBOCAN estimates of incidence and mortality worldwide for 36 cancers in 185 countries. CA Cancer J Clin 68: 394-424, 2018.

2. Ferlay J, Colombet M, Soerjomataram I, Mathers C, Parkin DM, Piñeros M, Znaor A and Bray F: Estimating the global cancer incidence and mortality in 2018: GLOBOCAN sources and methods. Int J Cancer 144: 1941-1953, 2019.

3. Sarmento-Ribeiro AB, Scorilas A, Gonçalves AC, Efferth T and Trougakos IP: The emergence of drug resistance to targeted cancer therapies: Clinical evidence. Drug Resist Updat 47: $100646,2019$.

4. Hall MD, Okabe M, Shen DW, Liang XJ and Gottesman MM: The role of cellular accumulation in determining sensitivity to platinum-based chemotherapy. Annu Rev Pharmacol Toxicol 48: 495-535, 2008.

5. Mikamori M, Yamada D, Eguchi H, Hasegawa S, Kishimoto T, Tomimaru Y, Asaoka T, Noda T, Wada H, Kawamoto K, et al: MicroRNA-155 controls exosome synthesis and promotes gemcitabine resistance in pancreatic ductal adenocarcinoma. Sci Rep 7: 42339, 2017.

6. Liu T, Chen G, Sun D, Lei M, Li Y, Zhou C, Li X, Xue W, Wang $\mathrm{H}$, Liu $\mathrm{C}$ and $\mathrm{Xu}$ J: Exosomes containing miR-21 transfer the characteristic of cisplatin resistance by targeting PTEN and PDCD4 in oral squamous cell carcinoma. Acta Biochim Biophys Sin (Shanghai) 49: 808-816, 2017.

7. Liu X, Lu Y, Xu Y, Hou S, Huang J, Wang B, Zhao J, Xia S, Fan S, Yu X, et al: Exosomal transfer of miR-501 confers doxorubicin resistance and tumorigenesis via targeting of BLID in gastric cancer. Cancer Lett 459: 122-134, 2019.

8. Wang L, Tong X, Zhou Z, Wang S, Lei Z, Zhang T, Liu Z, Zeng Y, Li C, Zhao J, et al: Circular RNA hsa_circ 0008305 (circPTK2) inhibits TGF- $\beta$-induced epithelial-mesenchymal transition and metastasis by controlling TIF $1 \gamma$ in non-small cell lung cancer. Mol Cancer 17: 140, 2018.

9. Liu J, Li Y, Tong J, Gao J, Guo Q, Zhang L, Wang B, Zhao H, Wang $\mathrm{H}$, Jiang E, et al: Long non-coding RNA-dependent mechanism to regulate heme biosynthesis and erythrocyte development. Nat Commun 9: 4386, 2018.

10. Cai Q, Wang S, Jin L, Weng M, Zhou D, Wang J, Tang Z and Quan Z: Long non-coding RNA GBCDRlnc1 induces chemoresistance of gallbladder cancer cells by activating autophagy. Mol Cancer 18: 82, 2019.
11. Hong X, Liu N, Liang Y, He Q, Yang X, Lei Y, Zhang P, Zhao Y, He S, Wang Y, et al: Circular RNA CRIM1 functions as a ceRNA to promote nasopharyngeal carcinoma metastasis and docetaxel chemoresistance through upregulating FOXQ1. Mol Cancer 19: 33, 2020.

12. Raposo G and Stoorvogel W: Extracellular vesicles: Exosomes, microvesicles, and friends. J Cell Biol 200: 373-383, 2013.

13. Li X, Wang Y, Wang Q, Liu Y, Bao W and Wu S: Exosomes in cancer: Small transporters with big functions. Cancer Lett 435: 55-65, 2018.

14. Bandari SK, Purushothaman A, Ramani VC, Brinkley GJ, Chandrashekar DS, Varambally S, Mobley JA, Zhang Y, Brown EE, Vlodavsky I and Sanderson RD: Chemotherapy induces secretion of exosomes loaded with heparanase that degrades extracellular matrix and impacts tumor and host cell behavior. Matrix Biol 65: 104-118, 2018.

15. Mashouri L, Yousefi H, Aref AR, Ahadi AM, Molaei F and Alahari SK: Exosomes: Composition, biogenesis, and mechanisms in cancer metastasis and drug resistance. Mol Cancer 18: 75, 2019.

16. Zhang H, Deng T, Liu R, Ning T, Yang H, Liu D, Zhang Q, Lin D, Ge S, Bai M, et al: CAF secreted miR-522 suppresses ferroptosis and promotes acquired chemo-resistance in gastric cancer. Mol Cancer 19: 43, 2020

17. Ponting CP, Oliver PL and Reik W: Evolution and functions of long noncoding RNAs. Cell 136: 629-641, 2009.

18. Wei LH and Guo JU: Coding functions of 'noncoding' RNAs. Science 367: 1074-1075, 2020.

19. Calin GA and Croce CM: MicroRNA signatures in human cancers. Nat Rev Cancer 6: 857-866, 2006.

20. Gregory PA, Bert AG, Paterson EL, Barry SC, Tsykin A, Farshid G, Vadas MA, Khew-Goodall Y and Goodall GJ: The miR-200 family and miR-205 regulate epithelial to mesenchymal transition by targeting ZEB1 and SIP1. Nat Cell Biol 10: 593-601, 2008.

21. Bandres E, Bitarte N, Arias F, Agorreta J, Fortes P, Agirre X, Zarate R, Diaz-Gonzalez JA, Ramirez N, Sola JJ, et al: microRNA-451 regulates macrophage migration inhibitory factor production and proliferation of gastrointestinal cancer cells. Clin Cancer Res 15: 2281-2290, 2009.

22. Baltruskeviciene E, Schveigert D, Stankevicius V, Mickys U, Zvirblis T, Bublevic J, Suziedelis K and Aleknavicius E: Down-regulation of miRNA-148a and miRNA-625-3p in colorectal cancer is associated with tumor budding. BMC Cancer 17: 607, 2017.

23. Gutschner T and Diederichs S: The hallmarks of cancer: A long non-coding RNA point of view. RNA Biol 9: 703-719, 2012.

24. Sanchez Calle A, Kawamura Y, Yamamoto Y, Takeshita F and Ochiya T: Emerging roles of long non-coding RNA in cancer. Cancer Sci 109: 2093-2100, 2018.

25. Ling H, Spizzo R, Atlasi Y, Nicoloso M, Shimizu M, Redis RS, Nishida N, Gafà R, Song J, Guo Z, et al: CCAT2, a novel noncoding RNA mapping to $8 \mathrm{q} 24$, underlies metastatic progression and chromosomal instability in colon cancer. Genome Res 23: 1446-1461, 2013.

26. Yuan JH, Yang F, Wang F, Ma JZ, Guo YJ, Tao QF, Liu F, Pan W, Wang TT, Zhou CC, et al: A long noncoding RNA activated by TGF-beta promotes the invasion-metastasis cascade in hepatocellular carcinoma. Cancer Cell 25: 666-681, 2014.

27. Niu Y, Ma F, Huang W, Fang S, Li M, Wei T and Guo L: Long non-coding RNA TUG1 is involved in cell growth and chemoresistance of small cell lung cancer by regulating LIMK2b via EZH2. Mol Cancer 16: 5, 2017.

28. YiRen H, YingCong Y, Sunwu Y, Keqin L, Xiaochun T, Senrui C, Ende C, XiZhou L and Yanfan C: Long noncoding RNA MALAT1 regulates autophagy associated chemoresistance via miR-23b-3p sequestration in gastric cancer. Mol Cancer 16: $174,2017$.

29. Sanger HL, Klotz G, Riesner D, Gross HJ and Kleinschmidt AK: Viroids are single-stranded covalently closed circular RNA molecules existing as highly base-paired rod-like structures. Proc Natl Acad Sci USA 73: 3852-3856, 1976.

30. Li Z, Huang C, Bao C, Chen L, Lin M, Wang X, Zhong G, Yu B, $\mathrm{Hu}$ W, Dai L, et al: Exon-intron circular RNAs regulate transcription in the nucleus. Nat Struct Mol Biol 22: 256-264, 2015.

31. Zhang Y, Zhang XO, Chen T, Xiang JF, Yin QF, Xing YH, Zhu S, Yang $L$ and Chen LL: Circular intronic long noncoding RNAs. Mol Cell 51: 792-806, 2013.

32. Guarnerio J, Bezzi M, Jeong JC, Paffenholz SV, Berry K, Naldini MM, Lo-Coco F, Tay Y, Beck AH and Pandolfi PP: Oncogenic role of fusion-circRNAs derived from cancer-associated chromosomal translocations. Cell 166: 1055-1056, 2016. 
33. Li Y, Zheng Q, Bao C, Li S, Guo W, Zhao J, Chen D, Gu J, He X and Huang S: Circular RNA is enriched and stable in exosomes: A promising biomarker for cancer diagnosis. Cell Res 25 981-984, 2015

34. Gao J, Dai C, Yu X, Yin XB and Zhou F: Circ-TCF4.85 silencing inhibits cancer progression through microRNA-486-5p-targeted inhibition of ABCF2 in hepatocellular carcinoma. Mol Oncol 14: 447-461, 2020.

35. Wang YG, Wang T, Ding M, Xiang SH, Shi M and Zhai B: hsa_circ 0091570 acts as a ceRNA to suppress hepatocellular cancer progression by sponging hsa-miR-1307. Cancer Lett 460: $128-138,2019$.

36. Harding C, Heuser J and Stahl P: Receptor-mediated endocytosis of transferrin and recycling of the transferrin receptor in rat reticulocytes. J Cell Biol 97: 329-339, 1983.

37. Pan BT and Johnstone RM: Fate of the transferrin receptor during maturation of sheep reticulocytes in vitro: Selective externalization of the receptor. Cell 33: 967-978, 1983

38. Wang M, Zhou L, Yu F, Zhang Y, Li P and Wang K: The functional roles of exosomal long non-coding RNAs in cancer. Cell Mol Life Sci 76: 2059-2076, 2019.

39. Colombo M, Moita C, van Niel G, Kowal J, Vigneron J, Benaroch P, Manel N, Moita LF, Théry C and Raposo G: Analysis of ESCRT functions in exosome biogenesis, composition and secretion highlights the heterogeneity of extracellular vesicles. J Cell Sci 126: 5553-5565, 2013.

40. Barile L and Vassalli G: Exosomes: Therapy delivery tools and biomarkers of diseases. Pharmacol Ther 174: 63-78, 2017.

41. Khare D, Or R, Resnick I, Barkatz C, Almogi-Hazan O and Avni B: Mesenchymal stromal cell-derived exosomes affect mRNA expression and function of B-lymphocytes. Front Immunol 9: 3053, 2018

42. Burrello J, Monticone S, Gai C, Gomez Y, Kholia S and Camussi G: Stem cell-derived extracellular vesicles and immune-modulation. Front Cell Dev Biol 4: 83, 2016.

43. Jayaseelan VP: Emerging role of exosomes as promising diagnostic tool for cancer. Cancer Gene Ther 27: 395-398, 2020.

44. Meldolesi J: Exosomes and ectosomes in intercellular communication. Curr Biol 28: R435-R444, 2018.

45. Lakkaraju A and Rodriguez-Boulan E: Itinerant exosomes: Emerging roles in cell and tissue polarity. Trends Cell Biol 18: 199-209, 2008

46. Kahroba H, Hejazi MS and Samadi N: Exosomes: From carcinogenesis and metastasis to diagnosis and treatment of gastric cancer. Cell Mol Life Sci 76: 1747-1758, 2019.

47. Li Z, Chen Z, Hu G and Jiang Y: Roles of circular RNA in breast cancer: Present and future. Am J Transl Res 11: 3945-3954, 2019

48. Zeng A, Wei Z, Yan W, Yin J, Huang X, Zhou X, Li R, Shen F, $\mathrm{Wu} \mathrm{W}$, Wang $\mathrm{X}$ and You Y: Exosomal transfer of miR-151a enhances chemosensitivity to temozolomide in drug-resistant glioblastoma. Cancer Lett 436: 10-21, 2018.

49. Jin G, Liu Y, Zhang J, Bian Z, Yao S, Fei B, Zhou L, Yin Y and Huang Z: A panel of serum exosomal microRNAs as predictive markers for chemoresistance in advanced colorectal cancer. Cancer Chemother Pharmacol 84: 315-325, 2019

50. Qin X, Guo H, Wang X, Zhu X, Yan M, Wang X, Xu Q, Shi J, Lu E, Chen W and Zhang J: Exosomal miR-196a derived from cancer-associated fibroblasts confers cisplatin resistance in head and neck cancer through targeting CDKN1B and ING5. Genome Biol 20: 12, 2019.

51. Yin J, Zeng A, Zhang Z, Shi Z, Yan W and You Y: Exosomal transfer of miR-1238 contributes to temozolomide-resistance in glioblastoma. EBioMedicine 42: 238-251, 2019.

52. Ji R, Zhang X, Gu H, Ma J, Wen X, Zhou J, Qian H, Xu W, Qian J and Lin J: miR-374a-5p: A new target for diagnosis and drug resistance therapy in gastric cancer. Mol Ther Nucleic Acids 18 : 320-331, 2019

53. Wang $G$, Zhao W, Wang H, Qiu G, Jiang Z, Wei G and Li X: Exosomal MiR-744 inhibits proliferation and sorafenib chemoresistance in hepatocellular carcinoma by targeting PAX2. Med Sci Monit 25: 7209-7217, 2019.

54. Liu Y, Tan J, Ou S, Chen J and Chen L: Adipose-derived exosomes deliver miR-23a/b to regulate tumor growth in hepatocellular cancer by targeting the VHL/HIF axis. J Physiol Biochem 75: 391-401, 2019.

55. Ren D, Lin B, Zhang X, Peng Y, Ye Z, Ma Y, Liang Y, Cao L, Li X, Li R, et al: Maintenance of cancer stemness by miR-196b-5p contributes to chemoresistance of colorectal cancer cells via activating STAT3 signaling pathway. Oncotarget 8: 49807-49823, 2017.
56. Chen WX, Xu LY, Qian Q, He X, Peng WT, Zhu YL and Cheng L: Analysis of miRNA signature differentially expressed in exosomes from adriamycin-resistant and parental human breast cancer cells. Biosci Rep 38: BSR20181090, 2018.

57. Zheng P, Chen L, Yuan X, Luo Q, Liu Y, Xie G, Ma Y and Shen L: Exosomal transfer of tumor-associated macrophage-derived miR-21 confers cisplatin resistance in gastric cancer cells. J Exp Clin Cancer Res 36: 53, 2017.

58. $\mathrm{Li} \mathrm{H}$ and $\mathrm{Li} \mathrm{F}$ : Exosomes from BM-MSCs increase the population of CSCs via transfer of miR-142-3p. Br J Cancer 119: 744-755, 2018

59. Deng X, Ruan H, Zhang X, Xu X, Zhu Y, Peng H, Zhang X, Kong $\mathrm{F}$ and Guan M: Long noncoding RNA CCAL transferred from fibroblasts by exosomes promotes chemoresistance of colorectal cancer cells. Int J Cancer 146: 1700-1716, 2020.

60. Kulkarni B, Kirave P, Gondaliya P, Jash K, Jain A, Tekade RK and Kalia K: Exosomal miRNA in chemoresistance, immune evasion, metastasis and progression of cancer. Drug Discov Today 24: 2058-2067, 2019.

61. Au Yeung CL, Co NN, Tsuruga T, Yeung TL, Kwan SY, Leung CS, Li Y, Lu ES, Kwan K, Wong KK, et al: Exosomal transfer of stroma-derived miR21 confers paclitaxel resistance in ovarian cancer cells through targeting APAF1. Nat Commun 7: 11150, 2016.

62. Richards KE, Zeleniak AE, Fishel ML, Wu J, Littlepage LE and Hill R: Cancer-associated fibroblast exosomes regulate survival and proliferation of pancreatic cancer cells. Oncogene 36: 1770-1778, 2017.

63. Nio K, Yamashita T and Kaneko S: The evolving concept of liver cancer stem cells. Mol Cancer 16: 4, 2017.

64. Santos JC, Lima NDS, Sarian LO, Matheu A, Ribeiro ML and Derchain SFM: Exosome-mediated breast cancer chemoresistance via miR-155 transfer. Sci Rep 8: 829, 2018.

65. Shen M, Dong C, Ruan X, Yan W, Cao M, Pizzo D, Wu X, Yang L, Liu L, Ren X and Wang SE: Chemotherapy-induced extracellular vesicle miRNAs promote breast cancer stemness by targeting ONECUT2. Cancer Res 79: 3608-3621, 2019.

66. Liu T, Zhang X, Du L, Wang Y, Liu X, Tian H, Wang L, Li P, Zhao Y, Duan W, et al: Exosome-transmitted miR-128-3p increase chemosensitivity of oxaliplatin-resistant colorectal cancer. Mol Cancer 18: 43, 2019.

67. Wang M, Qiu R, Yu S, Xu X, Li G, Gu R, Tan C, Zhu W and Shen B: Paclitaxel-resistant gastric cancer MGC-803 cells promote epithelial-to-mesenchymal transition and chemoresistance in paclitaxel-sensitive cells via exosomal delivery of miR-155-5p. Int J Oncol 54: 326-338, 2019.

68. Ma Y, Yuwen D, Chen J, Zheng B, Gao J, Fan M, Xue W, Wang Y, $\mathrm{Li} \mathrm{W}$, Shu Y, et al: Exosomal transfer of cisplatin-induced miR-425-3p confers cisplatin resistance In NSCLC through activating autophagy. Int J Nanomedicine 14: 8121-8132, 2019.

69. Deng Z, Rong Y, Teng Y, Zhuang X, Samykutty A, Mu J, Zhang L, Cao P, Yan J, Miller D and Zhang HG: Exosomes miR-126a released from MDSC induced by DOX treatment promotes lung metastasis. Oncogene 36: 639-651, 2017.

70. Zhu X, Shen H, Yin X, Yang M, Wei H, Chen Q, Feng F, Liu Y, $\mathrm{Xu} \mathrm{W}$ and Li Y: Macrophages derived exosomes deliver miR-223 to epithelial ovarian cancer cells to elicit a chemoresistant phenotype. J Exp Clin Cancer Res 38: 81, 2019.

71. Adamczyk A, Kruczak A, Harazin-Lechowska A, Ambicka A, Grela-Wojewoda A, Domagała-Haduch M, Janecka-Widła A, Majchrzyk K, Cichocka A, Ryś J and Niemiec J: Relationship between HER 2 gene status and selected potential biological features related to trastuzumab resistance and its influence on survival of breast cancer patients undergoing trastuzumab adjuvant treatment. Onco Targets Ther 11: 4525-4535, 2018.

72. Han M, Gu Y, Lu P, Li J, Cao H, Li X, Qian X, Yu C, Yang Y, Yang $\mathrm{X}$, et al: Exosome-mediated lncRNA AFAP1-AS1 promotes trastuzumab resistance through binding with AUF1 and activating ERBB2 translation. Mol Cancer 19: 26, 2020.

73. Zheng Z, Chen M, Xing P, Yan X and Xie B: Increased expression of exosomal AGAP2-AS1 (AGAP2 antisense RNA 1) in breast cancer cells inhibits trastuzumab-induced cell cytotoxicity. Med Sci Monit 25: 2211-2220, 2019.

74. Dong H, Wang W, Chen R, Zhang Y,Zou K, Ye M, He X, Zhang F and Han J: Exosome-mediated transfer of lncRNA-SNHG14 promotes trastuzumab chemoresistance in breast cancer. Int J Oncol 53: 1013-1026, 2018

75. Wang X, Pei X, Guo G, Qian X, Dou D, Zhang Z, Xu X and Duan $X$ : Exosome-mediated transfer of long noncoding RNA H19 induces doxorubicin resistance in breast cancer. J Cell Physiol 235: 6896-6904, 2020. 
76. Ren J, Ding L, Zhang D, Shi G, Xu Q, Shen S, Wang Y, Wang T and Hou Y: Carcinoma-associated fibroblasts promote the stemness and chemoresistance of colorectal cancer by transferring exosomal lncRNA H19. Theranostics 8: 3932-3948, 2018.

77. Ramachandran I, Thavathiru E, Ramalingam S, Natarajan G, Mills WK, Benbrook DM, Zuna R, Lightfoot S, Reis A, Anant S and Queimado L: Wnt inhibitory factor 1 induces apoptosis and inhibits cervical cancer growth, invasion and angiogenesis in vivo. Oncogene 31: 2725-2737, 2012.

78. Tenbaum SP, Ordóñez-Morán P, Puig I, Chicote I, Arqués O, Landolfi S, Fernández Y, Herance JR, Gispert JD Mendizabal L, et al: $\beta$-catenin confers resistance to PI3K and AKT inhibitors and subverts FOXO3a to promote metastasis in colon cancer. Nat Med 18: 892-901, 2012

79. Arend RC,Londoño-Joshi AI, Straughn JM Jr and Buchsbaum DJ: The Wnt/ $\beta$-catenin pathway in ovarian cancer: A review. Gynecol Oncol 131: 772-779, 2013

80. Wickström M, Dyberg C, Milosevic J, Einvik C, Calero R, Sveinbjörnsson B, Sandén E, Darabi A, Siesjö P, Kool M, et al: Wnt/ $\beta$-catenin pathway regulates MGMT gene expression in cancer and inhibition of Wnt signalling prevents chemoresistance. Nat Commun 6: 8904, 2015.

81. Li Z, Jiang P, Li J, Peng M, Zhao X, Zhang X, Chen K, Zhang Y, Liu H, Gan L, et al: Tumor-derived exosomal lnc-Sox2ot promotes EMT and stemness by acting as a ceRNA in pancreatic ductal adenocarcinoma. Oncogene 37: 3822-3838, 2018.

82. Wang J, Lv B, Su Y, Wang X, Bu J and Yao L: Exosome-mediated transfer of lncRNA HOTTIP promotes cisplatin resistance in gastric cancer cells by regulating HMGA1/miR-218 axis. Onco Targets Ther 12: 11325-11338, 2019.

83. Kang M, Ren M, Li Y, Fu Y, Deng M and Li C: Exosome-mediated transfer of lncRNA PART1 induces gefitinib resistance in esophageal squamous cell carcinoma via functioning as a competing endogenous RNA. J Exp Clin Cancer Res 37: 171, 2018.

84. Zhang Z, Yin J, Lu C, Wei Y, Zeng A and You Y: Exosomal transfer of long non-coding RNA SBF2-AS1 enhances chemoresistance to temozolomide in glioblastoma. J Exp Clin Cancer Res 38: 166, 2019.

85. Zhang W, Cai X, Yu J, Lu X, Qian Q and Qian W: Exosome-mediated transfer of lncRNA RP11-838N2.4 promotes erlotinib resistance in non-small cell lung cancer. Int J Oncol 53: 527-538, 2018

86. Zhao Z, Ji M, Wang Q, He N and Li Y: Circular RNA Cdrlas upregulates SCAI to suppress cisplatin resistance in ovarian cancer via miR-1270 suppression. Mol Ther Nucleic Acids 18: 24-33, 2019.

87. Hon KW, Ab-Mutalib NS, Abdullah NMA, Jamal R and Abu N: Extracellular Vesicle-derived circular RNAs confers chemoresistance in colorectal cancer. Sci Rep 9: 16497, 2019.

88. Wang X, Zhang H, Yang H, Bai M, Ning T, Deng T, Liu R, Fan Q, Zhu K, Li J, et al: Exosome-delivered circRNA promotes glycolysis to induce chemoresistance through the miR-122-PKM2 axis in colorectal cancer. Mol Oncol 14: 539-555, 2020
89. Ding C, Yi X, Wu X, Bu X, Wang D, Wu Z, Zhang G, Gu J and Kang D: Exosome-mediated transfer of circRNA CircNFIX enhances temozolomide resistance in glioma. Cancer Lett 479: $1-12,2020$

90. Wang X, Zhang H, Bai M, Ning T, Ge S, Deng T, Liu R, Zhang L, Ying $\mathrm{G}$ and $\mathrm{Ba} \mathrm{Y}$ : Exosomes serve as nanoparticles to deliver anti-miR-214 to reverse chemoresistance to cisplatin in gastric cancer. Mol Ther 26: 774-783, 2018.

91. Jingyue S, Xiao W, Juanmin Z, Wei L, Daoming L and Hong X: TFAP2E methylation promotes 5-fluorouracil resistance via exosomal miR-106a-5p and miR-421 in gastric cancer MGC-803 cells. Mol Med Rep 20: 323-331, 2019.

92. Patel GK, Khan MA, Bhardwaj A, Srivastava SK, Zubair H, Patton MC, Singh S, Khushman M and Singh AP: Exosomes confer chemoresistance to pancreatic cancer cells by promoting ROS detoxification and miR-155-mediated suppression of key gemcitabine-metabolising enzyme, DCK. Br J Cancer 116: 609-619, 2017.

93. Xu Y and Zhu M: Novel exosomal miR-46146 transfer oxaliplatin chemoresistance in colorectal cancer. Clin Transl Oncol 22 1105-1116, 2020

94. Chen WX, Xu LY, Qian Q, He X, Peng WT, Fan WQ, Zhu YL, Tang JH and Cheng L: $d$ Rhamnose $\beta$-hederin reverses chemoresistance of breast cancer cells by regulating exosome-mediated resistance transmission. Biosci Rep 38: BSR20180110, 2018.

95. Kanlikilicer P, Bayraktar R, Denizli M, Rashed MH, Ivan C, Aslan B, Mitra R, Karagoz K, Bayraktar E, Zhang X, et al: Exosomal miRNA confers chemo resistance via targeting Cav1/p-gp/M2-type macrophage axis in ovarian cancer. EBioMedicine 38: 100-112, 2018.

96. Weiner-Gorzel K, Dempsey E, Milewska M, McGoldrick A, Toh V, Walsh A, Lindsay S, Gubbins L, Cannon A, Sharpe D, et al: Overexpression of the microRNA miR-433 promotes resistance to paclitaxel through the induction of cellular senescence in ovarian cancer cells. Cancer Med 4: 745-758, 2015.

97. Zhu L, Zhu Y, Han S, Chen M, Song P, Dai D, Xu W, Jiang T, Feng L, Shin VY, et al: Impaired autophagic degradation of lncRNA ARHGAP5-AS1 promotes chemoresistance in gastric cancer. Cell Death Dis 10: 383, 2019

98. Lee JW, Guan W, Han S, Hong DK, Kim LS and Kim H MicroRNA-708-3p mediates metastasis and chemoresistance through inhibition of epithelial-to-mesenchymal transition in breast cancer. Cancer Sci 109: 1404-1413, 2018.

99. Shen Z, Zhou L, Zhang C and Xu J: Reduction of circular RNA Foxo3 promotes prostate cancer progression and chemoresistance to docetaxel. Cancer Lett 468: 88-101, 2020.

This work is licensed under a Creative Commons Attribution-NonCommercial-NoDerivatives 4.0 International (CC BY-NC-ND 4.0) License. 